\title{
Corporate engagement with the natural environment
}

To the Editor - Folke et al. ${ }^{1}$ provide an important perspective highlighting the outsized impact of transnational corporations (TNCs) on the biosphere. In doing so they remind us that organizations are a prominent meso-scale social phenomena, no less important for sustainability than governments and individuals.

While clear-eyed about the willingness of TNCs to actively steward the biosphere, Folke et al. nonetheless provide a cautiously optimistic narrative based on six features of emergent, systemic change. However, there is room for a more nuanced conceptualization of TNCs that does not gloss over salient features such as industry affiliation, competitive strategy and organizational complexity. Perceiving TNCs as uniform rather than heterogeneous obscures potential pathways to encouraging, incentivizing or coercing them towards stewardship. Management research on organizations and the natural environment ${ }^{2}$ can identify effective approaches, tailored to different TNC archetypes.

Folke et al. emphasize the outsized impact of upstream extractive and commodity industries such as agriculture and mining, but a consideration of the full value chain suggests that leverage points for systemic change may lie elsewhere. In the food sector, for example, restaurants and retailers, including traditionally meat-based fast-food restaurant chains, are embracing and even extolling plant-based menu items, which require very low switching costs. At the same time, meat processors, further back in the value chain, are resisting this shift and fighting a rear-guard battle to position animal meat as a non-substitutable product. In their segment of the value chain, biodiversity stewardship is more of a (shortterm) threat than an opportunity.

The oil and gas sector, by contrast, is more vertically integrated, meaning that TNCs typically span more of the value chain. In this sector, sustainability strategies derive from a corporation's unique 'core competencies'. An energy company that is investing in renewable energy, and is therefore better positioned to thrive in the transition to a low-carbon economy, for instance, is less



Fig. 1 | Diverse levels of engagement with biodiversity stewardship in the industry sectors comprising the global meat value chain. Biodiversity stewardship is non-uniform along value chains. On the left, oligopolistic structure, commodity products and large environmental footprint generally reduce the likelihood that machinery, chemical and seed companies will go 'beyond compliance' on biodiversity stewardship. On the right, differentiated product offerings, proximity to consumers and lower industry concentration make biodiversity stewardship a viable competitive position for retailers, if aligned with a TNC's core competencies. Figure adapted with permission from ref. ${ }^{10}$, AT Kearney.

likely to lobby against efforts to curtail fossil fuel emissions, and may in fact support them $^{3}$. In sum, contingent on industry and core competencies, a TNC may perceive stewardship to be a risk management endeavour, a means of differentiation, an opportunity to reformulate a business model, or an existential threat ${ }^{4}$. See Fig. 1 for an illustration.

But even this portrayal is overly simplified, particularly for large TNCs, which often employ tens of thousands of people across dozens of countries. These complex entities rarely have strategies that coherently orient all their activities ${ }^{5}$. For example, many car manufacturers are developing low-carbon vehicles while at the same time lobbying for less-stringent emissions standards, making them both 'good' and 'bad' at the same time 6 . In fact, corporate sustainability is an exercise in managing essentially unresolvable tensions and paradoxes?

Finally, most TNC sustainability initiatives are process-based. Sustainability reporting and environmental accreditation are managerial tools, not environmental outcomes. Employing them does not guarantee that harms to the biosphere will actually decline ${ }^{8}$. In practice, organizational focus often shifts to "boxchecking' and compliance to standards as opposed to outcomes', a phenomenon management researchers call the 'goal- displacement trap'. Emerging output-based sustainability metrics (for example, www. sciencebasedtargets.org) might evade this trap. Interdisciplinary research to devise and deploy these types of metrics is one way for social and natural scientists to work together to promote bold corporate action towards biosphere stewardship.

\section{Dror Etzion (D)}

Desautels Faculty of Management, McGill University, Montreal, Quebec, Canada.

e-mail:dror.etzion@mcgill.ca

Published online: 28 February 2020 https://doi.org/10.1038/s41559-020-1142-5

\section{References}

1. Folke, C. et al. Nat. Ecol. Evol. 3, 1396-1403 (2019).

2. Bansal, P. \& Hoffman, A. J. The Oxford Handbook of Business and the Natural Environment (Oxford Univ. Press, 2012).

3. Delmas, M., Lim, J. \& Nairn-Birch, N. Acad. Manag. Disc. 2 175-197 (2016).

4. Reinhardt, F. L. Harv. Bus. Rev. 77, 149-157 (1999).

5. Brunsson, N. The Organization of Hypocrisy: Talk, Decisions and Actions in Organizations (John Wiley \& Sons, 1989).

6. Strike, V. M., Gao, J. \& Bansal, P. J. Int. Bus. Stud. 37, 850-862 (2006)

7. Schad, J. \& Bansal, P. J. Manag. Stud. 55, 1490-1506 (2018).

8. Delmas, M., Etzion, D. \& Nairn-Birch, N. Acad. Manag. Persp. 27, 255-267 (2013).

9. Wijen, F. Acad. Manag. Rev. 39, 302-323 (2014).

10. Gerhardt, C. et al. How Will Cultured Meat and Meat Alternatives Disrupt the Agricultural and Food Industry? (AT Kearney, 2019).

Competing interests

The author declares no competing interests. 